\title{
Cloning and characterization of a cDNA encoding a paired box protein, PAX7, from black sea bream, Acanthopagrus schlegelii
}

\author{
Jae Hoon Choi ${ }^{1}$, Dan Hee Han ${ }^{1}$ and Seung Pyo Gong ${ }^{1,2, *}$ \\ ${ }^{1}$ Department of Fisheries Biology, Pukyong National University, Busan 48513, Korea \\ ${ }^{2}$ Department of Marine-Biomaterials and Aquaculture, Pukyong National University, Busan 48513, Korea
}

Received December 3, 2021

Revised December 15, 2021

Accepted December 17, 2021

*Correspondence

Seung Pyo Gong

E-mail: gongsp@pknu.ac.kr

Author's Position and Orcid no.

Choi JH, PhD candidate,

https://orcid.org/0000-0003-3578-3167

Han DH, PhD candidate,

https://orcid.org/0000-0002-6700-2233

Gong SP, PhD, Professor,

https://orcid.org/0000-0002-9358-9568

\begin{abstract}
Paired box protein, PAX7, is a key molecule for the specification, maintenance and skeletal muscle regeneration of muscle satellite cells. In this study, we identified and characterized the cDNA and amino acid sequences of PAX7 from black sea bream (Acanthopagrus schlegelii) via molecular cloning and sequence analysis. A. schlegelii PAX7 cDNA was comprised of 1,524 bp encoding 507 amino acids and multiple sequence alignment analysis of the translated amino acids showed that it contained three domains including paired DNA-binding domain, homeobox domain and OAR domain which were well conserved across various animal species investigated. Pairwise Sequence Alignment indicated that $A$. schlegelii PAX7 had the same amino acid sequences with that of yellowfin seabream ( $A$. latus) and $99.8 \%$ identity and similarity with that of gilt-head bream (Sparus aurata). Molecular phylogenetic analysis confirmed that $A$. schlegelii PAX7 formed a monophyletic group with those of teleost and most closely related with those of the fish that belong to Sparidae family including $A$. latus and $S$. aurata. In the investigation of its tissue specific mRNA expression, the expression was specifically identified in skeletal muscle tissue and a weak expression was also shown in gonad tissue. The cultured cells derived from skeletal muscle tissues expressed PAX7 mRNA at early passage but the expression was not observed after several times of subculture.
\end{abstract}

Keywords: black sea bream, molecular characterization, PAX7, skeletal muscle

\section{INTRODUCTION}

Black sea bream (Acanthopagrus schlegelii) is one of major farmed fish in Korea and inhabits in Southeast Asia including Korea, Japan, and China (Zhou et al., 2011). Since they have a good taste and are perceived as a highclass fish, its demand and productivity increase consistently (Wang et al., 2019). To improve the productivity and quality of this fish as a food material, understanding the regulatory mechanism of skeletal muscle development of this fish is required.

Muscle satellite cells, also known as muscle stem cells, are the small quiescent cells located between the muscle fibre and the surrounding basement membrane and responsible for skeletal muscle regeneration (Zammit and Beauchamp, 2001; Montarras et al., 2013). In response to injury, these quiescent cells become activated, proliferate, and build new skeletal muscle (Bischoff and Heintz, 1994; Shi and Garry, 2006). It has been well known that paired box protein, PAX7, as a member of the paired box fam- 
ily of transcription factors, is expressed in mammalian muscle satellite cells (Dumont et al., 2015). In murine, it is essential for the specification, maintenance and skeletal muscle regeneration of muscle satellite cells (Rudnicki and Jaenisch, 1995; Dumont et al., 2015). Indeed, when PAX7 was deficient in mice, muscle satellite cells and myoblasts showed cell cycle arrest and dysregulated the myogenic regulatory factors (von Maltzahn et al., 2013). In fish, the zebrafish studies showed that $P A X 7$ positive cells migrated to injury and entered the cell cycle (Seger et al., 2011) and PAX7 mutant zebrafish were defective in adult skeletal muscle repair (Berberoglu et al., 2017). These indicate that zebrafish PAX7 plays a role in skeletal muscle regeneration implying that this gene is functionally conserved between mammals and fish. Many efforts have been made to reveal the characteristics and regulatory mechanism of this molecule in a number of terrestrial animals including human (Homo sapiens; Pawlikowski et al., 2009), mouse (Mus musculus; Nicklas et al., 2012), pig (Sus scrofa domesticus; Ding et al., 2017), cow (Bos Taurus; RamírezEspinosa et al., 2016), chicken (Gallus gallus; Halevy et al., 2004). Furthermore, some studies have shown the genetic information of PAX7 in several fish species including zebrafish (Danio rerio; Berberoglu et al., 2017), Rainbow trout (Oncorhynchus mykiss; Chapalamadugu et al., 2015), longtail knifefish (Sternopygus macrurus; Weber et al., 2012), and gilthead sea bream (Sparus aurata; García de la serrana et al., 2014). However, the basic information of A. schlegelii PAX7 has not been verified yet and thus should be revealed for further research and development of this fish as a food material.

Therefore, in this study, we performed molecular cloning and characterization of PAX7 cDNA from black sea bream, $A$. schlegelii. The cDNA sequence of the tentative PAX7 gene was identified by a conventional gene cloning and DNA sequencing and then the deduced sequences were characterized by multiple sequence alignment and phylogenetic tree analyses. Finally, its expression was evaluated in various tissues and the cultured cells derived from skeletal muscle tissues.

\section{MATERIALS AND METHODS}

\section{Fish}

Black sea bream (A. schlegelii) were managed in a 1-ton tank in the Laboratory of Cell Biotechnology, Pukyong
National University (Busan, Korea). Water temperature and salinity were maintained at $22^{\circ} \mathrm{C}$ and 33 psu, respectively. They were fed two times a day with an artificial diet for flounder (Woosung, Daejeon, Korea). Skeletal muscle tissues were collected for cDNA sequencing and primary explant culture from 11 months old fish with 11 to $13 \mathrm{~cm}$ body length. For the analysis of tissue-specific mRNA expression, 15 months old fish of $20 \mathrm{~cm}$ in body length were used to obtain a sufficient amount of gonad tissues that do not mature and thus can be hardly isolated in 11 months old fish. All procedures dealing with animals complied with the guidelines provided by Pukyong National University and the Institutional Animal Care and Use Committee (IACUC) of Pukyong National University approved our research proposal (approval No. PKNUIACUC-2021-32).

\section{cDNA Sequencing of PAX7 gene}

Total RNA was extracted from skeletal muscle tissues using Trizole ${ }^{\mathrm{TM}}$ reagent (Trizol; Thermo Fisher Scientific, MA, USA) and $1 \mu \mathrm{g}$ of total RNA were treated with DNase I (Sigma-Aldrich, St. Louis, MO) according to manufacturer's instructions. After that, the cDNA was synthesized using GoScript ${ }^{\mathrm{TM}}$ reverse transcription system (Promega, Madison, WI) and then subjected to polymerase chain reaction (PCR) with a specific primer set. The primers for the amplification of tentative PAX7 cDNA were designed by referring to the genome database of $A$. latus, aligned species with $A$. schlegelii, which is registered in National Center for Biotechnology Information (NCBI). Primer sequences used in this study were presented in Table 1. PCR conditions were as follows; initial denaturation $\left(94^{\circ} \mathrm{C}\right.$ for 3 minutes), 35 cycle amplification (denaturation; $95^{\circ} \mathrm{C}$ for 30 seconds, annealing; $57^{\circ} \mathrm{C}$ for 30 seconds, and elongation; $72^{\circ} \mathrm{C}$ for 1 minute and 45 seconds), and final elongation ( $72^{\circ} \mathrm{C}$ for 5 minutes). The PCR products were size-fractionated through $1.2 \%$ agarose gel (Lonza, Rockland, ME) electrophoresis for 20 minutes and visualized using an UV transilluminator (DAIHAN Scientific, Wonju, Korea). PCR bands were captured by Gel Documentation system (DAIHAN Scientific), extracted by GenoAid ${ }^{\mathrm{TM}}$ PCR/Gel combo kit (Genotech, Daejeon, Korea), and subcloned using TOPcloner ${ }^{\text {TM }}$ TA kit (Enzynomics, Daejeon, Korea) according to the manufacturer's instructions. The subcloned plasmids were prepped by FavorPrep ${ }^{\mathrm{TM}}$ plasmid Extraction Mini Kit (Favorgen Biotech Corporation, Pingtung coun- 
Table 1. Information of primers used in this study

\begin{tabular}{llcr}
\hline \multirow{2}{*}{ Genes } & \multicolumn{2}{c}{ Primer sequences $\left(5^{\prime} \rightarrow 3^{\prime}\right)$} & Product size (bp) \\
\cline { 2 - 3 } & Forward & Reverse & 1584 \\
PAX7 & ATGATGGCTACTTTACCAGGAACT & ACTTGATGGAGCATGGAGGA & 419 \\
GAPDH & GCATCTTGCACGACTAACTGC & TCACCGATGAAGTCGGAGGA & \\
\hline
\end{tabular}

try, Taiwan). Sequencing analysis was performed through a company specialized in sequencing service (CosmoGenetech, Seoul, Korea).

\section{Characterization of the deduced amino acid sequences}

Amino acid sequences of the cloned gene were translated by Bioedit 7.2 software (available to download at https://bioedit.software.informer.com/7.2/). The predictive domains of the constructed amino acids were investigated by PROSITE program (https://prosite.expasy.org). Multiple sequence alignment analysis was performed by Bioedit 7.2 software and the amino acid sequences from other animal species including teleost (A. latus, $S$. aurata, O. mykiss, D. rerio, Oryzias latipes, and O. melastigma), avian (G. gallus and Meleagris gallopavo), and mammals ( $H$. sapiens and M. musculus) were referenced from NCBI. To investigate the identities and similarities of the constructed amino acid sequences with those of other animal species, Pairwise Sequence Alignment (http://www.ebi. ac.uk/Tools/psa/emboss_needle/) was used. Molecular phylogenetic tree was constructed by Molecular Evolutionary Genetics Analysis (MEGA) X software 10.2.6 version (https://www.megasoftware.net/).

\section{Primary explant culture}

Skeletal muscle tissues isolated from $A$. schlegelii were washed 3 times with Dulbecco's phosphate buffered saline (DPBS; Gibco, Grand Island, NY) and dissected into small pieces of $1-2 \mathrm{~mm}$ in size using surgical blade. Around 10 to 15 tissue fragments were seeded onto a well of 6 well plate (SPL Life Sciences, Pocheon, Korea) and covered with cover glass to make them stick to the bottom of plate. Culture media consisted of Dulbecco's modified eagles medium (DMEM; Gibco) supplemented with $20 \mathrm{mM}$ HEPES (Sigma-Aldrich, St. Louis, MO), 20\% (v/v) fetal bovine serum (FBS; Gibco), and 1\% (v/v) penicillin and streptomycin (Gibco). Culture was performed in $28^{\circ} \mathrm{C}$ incubator with air atmosphere and media were changed every three days. The tissue fragments were removed after culturing for 7 days. When the cells reached to $80-90 \%$ confluency, subculture was conducted. For subculture, the cultured cells were washed with DPBS two times, dissociated with $0.05 \%$ trypsin-EDTA (Gibco), and collected by centrifugation (1,500 rpm, 4 mins). Then, the cells were suspended with culture media and split at 1:2 ratio on $0.1 \%$ gelatincoated dishes. Cell morphology was observed under an inverted microscope (TS100-F; Nikon, Tokyo, Japan).

\section{Reverse transcription-PCR (RT-PCR)}

Total RNA extraction, cDNA synthesis, PCR, and electrophoresis were performed by the protocols described above. The primers for $P A X 7$ were same with those used for cDNA cloning and the primers for $G A P D H$ which was used as an internal control were designed based on $A$. schlegelii GAPDH partial sequences (accession number: DQ399798.1) from NCBI. The same PCR conditions with those used for cDNA cloning were used but annealing temperature in $G A P D H$ amplification was differently set to $55^{\circ} \mathrm{C}$.

\section{RESULTS AND DISCUSSION}

Based on the sequencing data, it was shown that $A$. schlegelii PAX7 has open reading frame (ORF) consisting of $1,524 \mathrm{bp}$ that encode 507 amino acids (Fig. 1). Multiple sequence alignment analysis of the translated amino acids of PAX7 with those from other animal species demonstrated that PAX7 has three conserved domains including paired DNA-binding domain (35-167 a.a.), homeobox domain (219-279 a.a.) and OAR domain (481-493 a.a.) (Fig. 2). PAX7 is a pioneer factor, which can open chromatin structure and gain access to their target DNA sites in chromatin (Zaret and Carroll, 2011; Pelletier et al., 2021). In mouse, it was known that PAX7 contains two DNA binding domains (a paired domain and a homeodomain) and OAR domain (Pelletier et al., 2021). Paired domain and homeobox domain of PAX7 play a key role for chromatin opening at pioneer sites and gene activation 


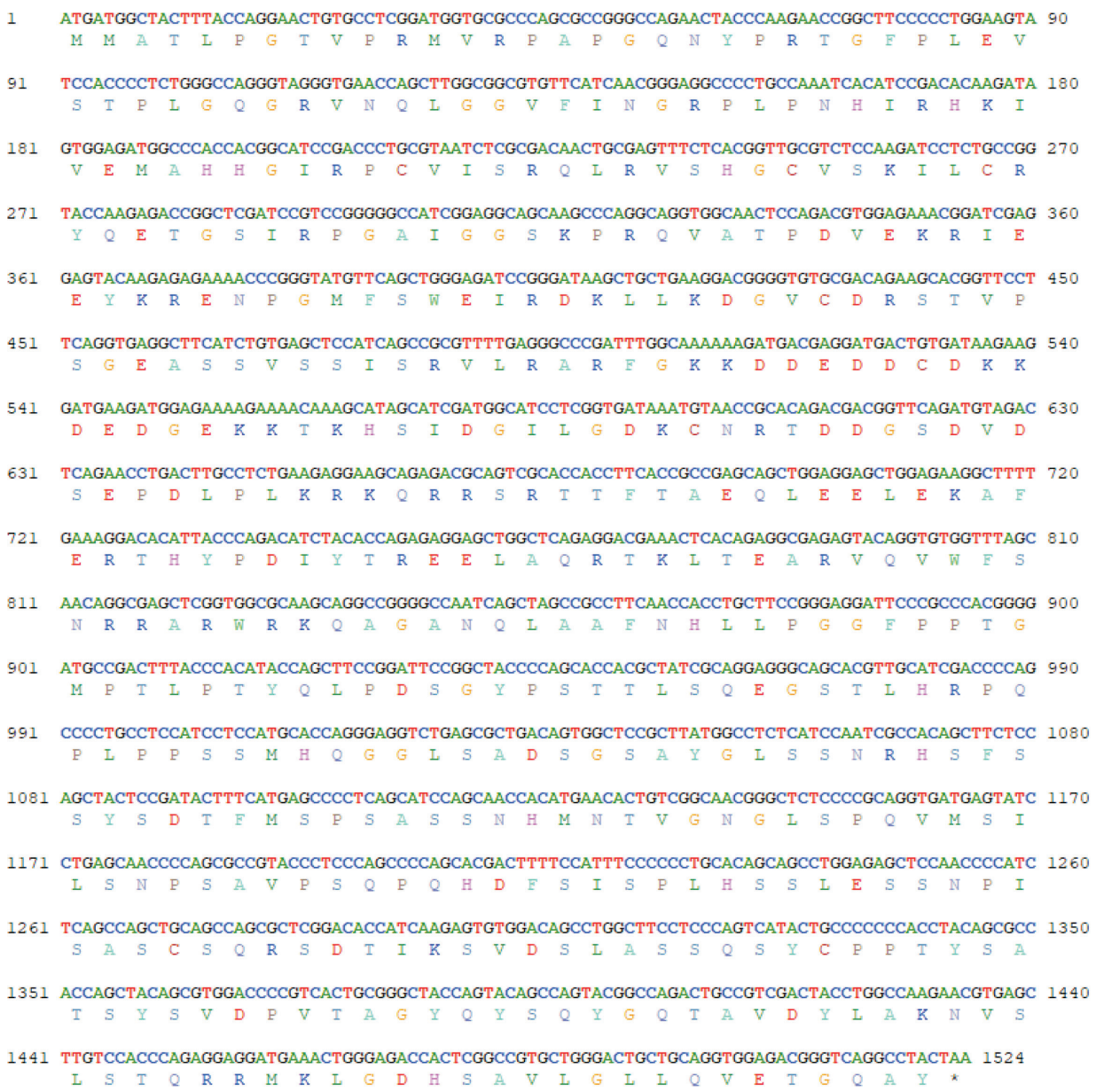

Fig. 1. cDNA and deduced amino acid sequences of black sea bream (Acanthopagrus schlegelii) PAX7. Numbers on left and right of figure indicate the number of nucleotides. One letter amino acid codes were presented beneath each of triple codons in nucleotide sequences. Asterisk indicates the stop codon. by recognizing different DNA target sites (Pelletier et al., 2021) and their intimate interaction contributes to optimal DNA binding (Jun and Desplan, 1996; Underhill and Gros, 1997). OAR domain that functions in DNA binding and transactivation is found in more than 30 pairedtype homeodomain proteins and known to play multiple regulatory roles although not yet well understood (Fan et al., 2019). PAX7 is the sole member that has OAR domain in the PAX family of transcription factors (Mayran et al., 2015). Our results showed that amino acid sequences of these three domains of $A$. schlegelii were highly similar with those of other animal species compared. Especially, in the comparison with mouse (M. musculus), 92.5\%, $100 \%$, and $92.3 \%$ sequences were same for paired domain, homeodomain, and OAR domain, respectively, reflecting that A. schlegelii PAX7 may have a similar biological function in the regulation of muscle satellite cells.

As shown in Table 2, Pairwise Sequence Alignment demonstrated that $A$. schlegelii PAX7 had the same amino acid sequences with that of yellowfin seabream (A. latus) that belongs to same genus and showed $99.8 \%$ identity and similarity with that of gilt-head bream ( $S$. aurata) that belongs to same family, Sparidae. Moreover, it showed a high identity and similarity with those of the other teleost including $O$. mykiss, D. rerio, O. latipes, and O. melastigma ranging from $94.3 \%$ to $98.2 \%$ and from $96.5 \%$ to $98.8 \%$, respectively. In the comparison with avian and mammals, relatively low values than those in the comparison with teleost were identified $(77.8 \%$ to $85.6 \%$ in identify and $84.5 \%$ to $90 \%$ in similarity). Molecular phylogenetic analysis confirmed that A. schlegelii PAX7 formed a monophyletic group with teleost and most closely related with the fish of Sparidae family, A. latus and S. aurata (Fig. 3).

To investigate PAX7 mRNA expression in various tissues including skeletal muscle, heart, gill, intestine, spleen, fin, liver, brain, and gonad, cDNA samples derived from each tissue were subjected to RT-PCR. GAPDH expression was also evaluated as an internal control. As a result, gene expression was identified in skeletal muscle and gonad tissues, but gonad tissue showed very weak expression (Fig. 
Acanthopagrus schlegelii Acanthopagrus latus Sparus aurata Oncorhynchus mykiss Danio rerio

Oryzias latipes

Oryzias melastigma

Gallus gallus

Meleagris gallopavo

Homo sapiens

Mus musculus

Acanthopagrus schlegelii Acanthopagrus latus Sparus aurata

Oncorhynchus mykiss

Danio rerio

Oryzias latipes

Oryzias melastigma

Gallus gallus

Meleagris gallopavo

Homo sapiens

Mus musculus

Acanthopagrus schlegelii

Acanthopagrus latus

Sparus aurata

Oncorhynchus mykiss

Danio rerio

Oryzias latipes

Oryzias melastigma

Gallus gallus

Meleagris gallopavo

Homo sapiens

Mus musculus

Acanthopagrus schlegelii Acanthopagrus latus Sparus aurata

Oncorhynchus mykiss

Danio rerio

Oryzias latipes

Oryzias melastigma

Gallus gallus

Meleagris gallopavo

Homo sapiens

Mus musculus

Acanthopagrus schlegeli Acanthopagrus latus

Sparus aurata

Oncorhynchus mykiss

Danio rerio

Oryzias latipes

Oryzias melastigma

Gallus gallus

Meleagris gallopavo

Homo sapiens

Mus musculus

Acanthopagrus schlegeli Acanthopagrus latus Sparus aurata

Oncorhynchus mykiss

Danio rerio

Oryzias latipes

Oryzias melastigma

Gallus gallus

Meleagris gallopavo

Homo sapiens

Mus musculus
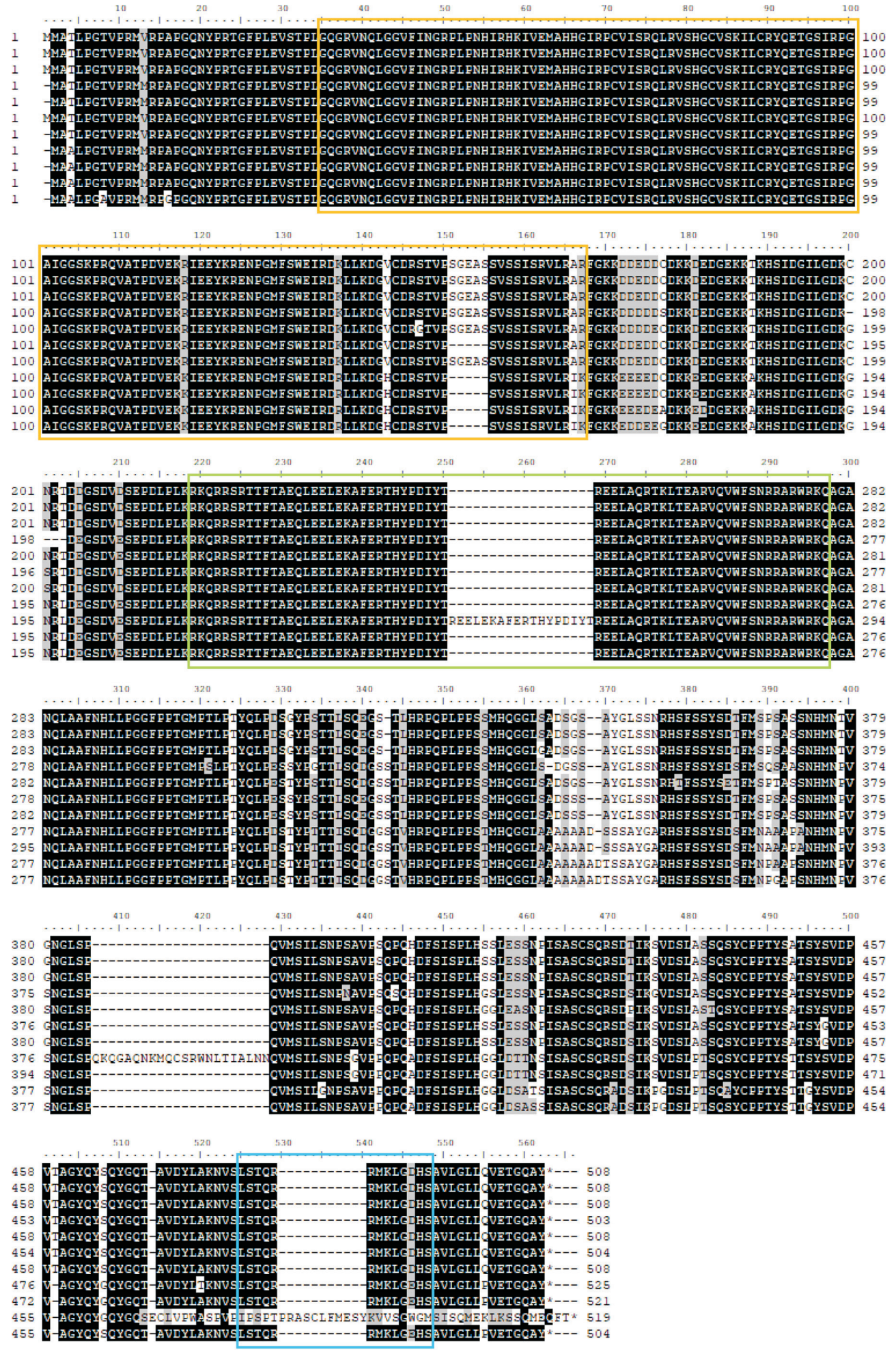

Fig. 2. Multiple sequence alignment analysis of PAX7 amino acid sequences of Acanthopagrus schlegelii with those of other teleost, avian, and mammalian species. The result was based on the following sequence data: A. latus (XP_036957057.1), Sparus aurata (XP_030276716.1), Oncorhynchus mykiss (NP_001245266.1), Danio rerio (NP_571400.1), Oryzias latipes (XP_011473129.1), O. melastigma (XP_024125911.1), Gallus gallus (NP_990396), Meleagris gallopavo (ADA61179), Homo sapiens (AAI21167.1), Mus musculus (NP_035169.1). Yellow line boxes (35-167 a.a.) indicate the predicted paired DNA-binding domain, green line box (219-279 a.a.) in-dicates the predicted homeobox domain and blue line box (481-493 a.a.) indicates the predicted OAR domain in A. schlegelii PAX7 amino acid sequences. Black shading: identical sequences; gray shading: somewhat similar sequences (threshold 80\%). 
Table 2. Percentages of identities and similarities of PAX7 amino acid sequences with other animal species

\begin{tabular}{lllcc}
\hline \multicolumn{1}{c}{ Common name } & Scientific name & Accession number & Identity (\%) & Similarity (\%) \\
\hline Yellowfin seabream & Acanthopagrus latus & XP_036957057.1 & 100 & 90 \\
Gilt-head bream & Sparus aurata & XP_030276716.1 & 99.8 & 94.3 \\
Rainbow trout & Oncorhynchus mykiss & NP_001245266.1 & 95.3 & 96.8 \\
Zebrafish & Danio rerio & NP_571400.1 & 97.4 & 97.3 \\
Medaka & Oryzias latipes & XP_011473129.1 & 98.2 & 98 \\
Marine medaka & Oryzias melastigma & XP_024125911.1 & 82.7 & 98.5 \\
Red junglefowl & Gallus gallus & NP_990396 & 83.5 \\
Wild turkey & Meleagris gallopavo & ADA61179 & 77.8 & 87.3 \\
Human & Homo sapiens & AAl21167.1 & 85.6 \\
Mouse & Mus musculus & NP_035169.1 & 84.5 \\
\hline
\end{tabular}

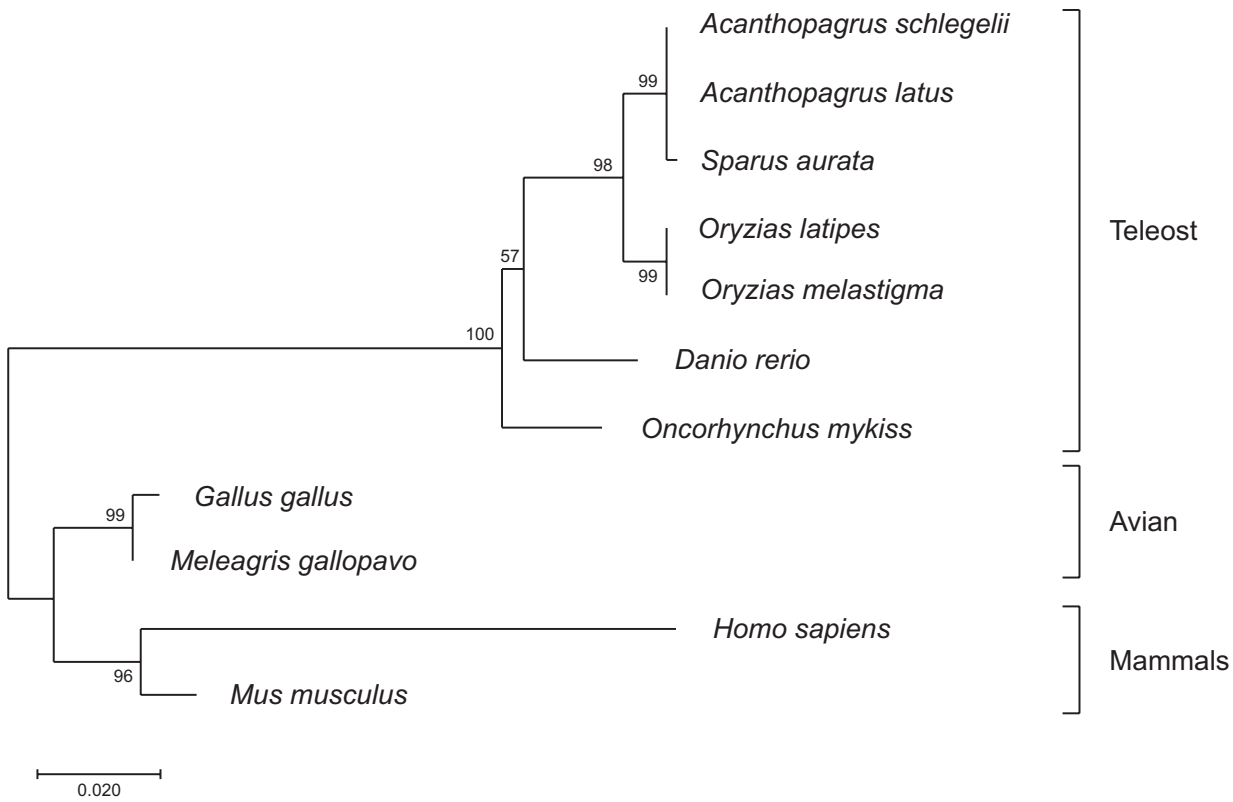

Fig. 3. A phylogenetic tree based on amino acid sequences of PAX7 from black sea bream (Acanthopagrus schlegelii), other teleost, avian, and mammalian species. Phylogenetic tree was constructed by neighbor-joining methods. Numbers on each node are bootstrap values from 1,000 replicates. Avian and mammalian species were used as the outgroups. The scale bar indicates a branch length of 0.02 .

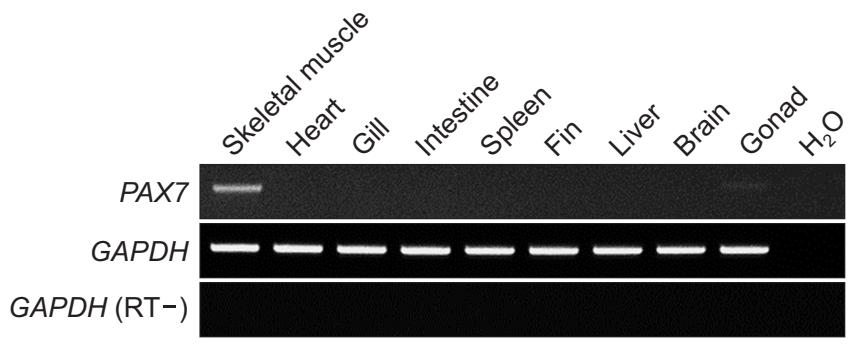

Fig. 4. Evaluation of tissue-specific expression of PAX7 mRNA. cDNAs prepared from nine tissues including muscle, heart, gill, intestine, spleen, fin, liver, brain, and gonad were subjected to RT-PCR analysis using PAX7 primers. GAPDH was used as an internal control. The expression of PAX7 mRNA was observed in muscle and gonad tissues.

4). Previously, PAX7 expression was identified in mouse testis, especially in spermatogonia at low level (Aloisio et al., 2014). Moreover, it was reported that PAX7 in goats promotes self-renewal of spermatogonia by upregulating several genes including Plzf, GFR 1, ID4 and OCT4 (Du et al., 2021). A. schlegelii has the hermaphroditic gonads in which testicular part and ovarian part are separated by connective tissue. As a protandrous fish, they mature as males for one to two spawning seasons and after that, half of them changes their sex to females (Wu et al., 2021). However, in non-spawning seasons including sexually immature period, the ovarian portion becomes major parts in their gonads (Huang et al., 2002). In this study, $20 \mathrm{~cm}$ in length and 15 months old $A$. schlegelii were used for the analysis of tissue-specific expression on September when it is non-spawning season after their spawning season from March to July in the southern sea of Korea (Kwon 
A

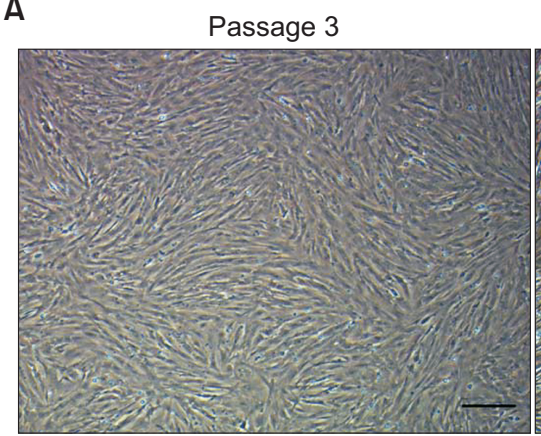

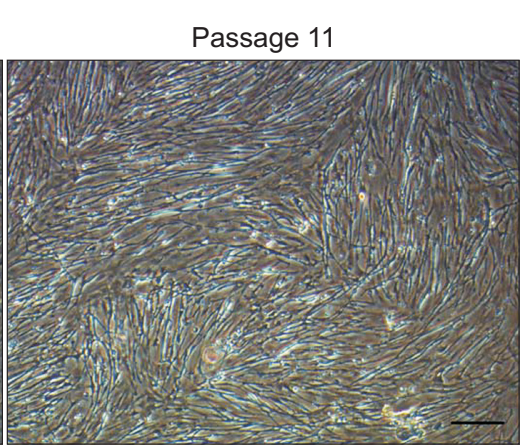

B

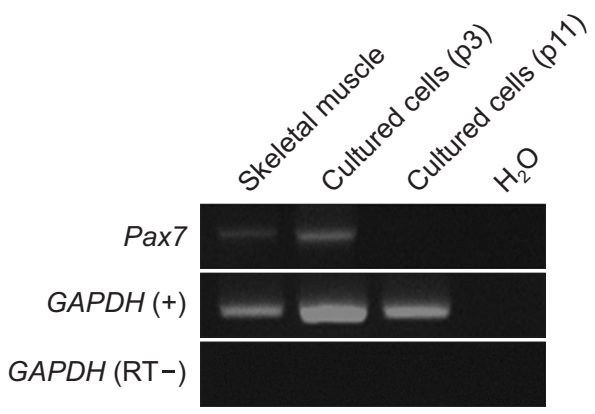

Fig. 5. Evaluation of PAX7 mRNA expression in the cultured cells derived from black sea bream (Acanthopagrus schlegelii) skeletal muscle tissues. (A) Morphology of muscle-derived cultured cells at passage 3 and 11. (B) PAX7 mRNA expression in the cultured cells. The cells at two different passages (passage 3 and 11) were subjected to RT-PCR analysis using PAX7 primers. GAPDH was used as an internal control. The cells expressed PAX7 at passage 3 but did not express at passage 11.

et al., 2009). Thus, the weak expression of PAX7 in gonads might be partially resulted from the gonadal structure in which ovarian portion was more dominant than testicular portion by seasonal variation. Collectively, these results indicated that $A$. schlegelii PAX7 isolated from this study had a specificity in its mRNA expression confirming the validity of the isolated cDNA.

PAX7 mRNA expression was also evaluated in the cultured cells derived from primary explant culture of skeletal muscle tissues. The cultured cells at passage 3 showed a flatten and fibroblast-like morphology and most cells had a single nucleus. The cells continuously proliferated via serial subculture but a number of cells changed their morphology to myotube-like form that had multiple nuclei when observed at passage 11 (Fig. 5A). The PAX7 mRNA expression was observed in passage 3 but not in passage 11 (Fig. 5B). Previous studies have demonstrated that stemness of muscle satellite cells could not be retained over early passage in vitro in the simple media consisting of basal media and FBS by showing the cellular differentiation at morphological and molecular levels with down-regulation of PAX7 expression (Halevy et al., 2004; Brzóska et al., 2009; García de la serrana et al., 2014; Choi et al., 2020). The similar results were shown in this experiment. A typical myogenic differentiation process of the cells was observed in morphology between passage 3 and 11, and simultaneously, PAX7 mRNA was not expressed at passage 11 indicating that the cells spontaneously differentiated during being cultured in the simple media. These suggest that $A$. schlegelii PAX7 similarly functions with those of other animal species and can be used as a valuable indicator for further study of $A$. schlegelii muscle satellite cells.

Taken together, we have isolated and characterized PAX7 from A. schlegelii and confirmed its tissue-specific expression in skeletal muscle and gonad tissues and the down-regulation of its mRNA expression in the cultured cells during continuous culture. Additional studies need to be carried out to verify its exact function in the regulation of the development and regeneration of skeletal muscle in A. schlegelii.

Author Contributions: J.H.C. performed the experiments and wrote the paper; D.H.H. performed the experiments; S.P.G. designed the experiments, analyzed the data and wrote the paper.

Funding: This research was supported by Basic Science Research Program through the National Research Foundation of Korea (NRF) funded by the Ministry of Education (2021R1I1A3041760).

Ethical Approval: The Institutional Animal Care and Use Committee (IACUC) of Pukyong National University approved our research proposal (approval No. PKNUIACUC-2021-32).

Consent to Participate: Not applicable.

Consent to Publish: Not applicable.

Availability of Data and Materials: Not applicable.

Acknowledgements: None. 
Conflicts of Interest: No potential conflict of interest relevant to this article was reported.

\section{REFERENCES}

Aloisio GM, Nakada Y, Saatcioglu HD, Peña CG, Baker MD, Tarnawa ED, Mukherjee J, Manjunath H, Bugde A, Sengupta AL, Amatruda JF, Cuevas I, Hamra FK, Castrillon DH. 2014. PAX7 expression defines germline stem cells in the adult testis. J. Clin. Invest. 124:3929-3944.

Berberoglu MA, Gallagher TL, Morrow ZT, Talbot JC, Hromowyk KJ, Tenente IM, Langenau DM, Amacher SL. 2017. Satellite-like cells contribute to pax7-dependent skeletal muscle repair in adult zebrafish. Dev. Biol. 424:162-180.

Bischoff R and Heintz C. 1994. Enhancement of skeletal muscle regeneration. Dev. Dyn. 201:41-54.

Brzóska E, Przewoźniak M, Grabowska I, Jańczyk-Ilach K, Moraczewski J. 2009. Pax3 and Pax7 expression during myoblast differentiation in vitro and fast and slow muscle regeneration in vivo. Cell Biol. Int. 33:483-492.

Chapalamadugu KC, Murdoch BM, Robison BD, Hill RA, Murdoch GK. 2015. Oncorhynchus mykiss pax7 sequence variations with comparative analyses against other teleost species. Springerplus 4:263.

Choi KH, Yoon JW, Kim M, Jeong J, Ryu M, Park S, Jo C, Lee CK. 2020. Optimization of culture conditions for maintaining pig muscle stem cells in vitro. Food Sci. Anim. Resour. 40:659667.

Ding S, Wang F, Liu Y, Li S, Zhou G, Hu P. 2017. Characterization and isolation of highly purified porcine satellite cells. Cell Death Discov. 3:17003.

Du X, Wu S, Wei Y, Yu X, Ma F, Zhai Y, Yang D, Zhang M, Liu W, Zhu H, Wu J, Liao M, Li N, Bai C, Li G, Hua J. 2021. PAX7 promotes CD49f-positive dairy goat spermatogonial stem cells' self-renewal. J. Cell. Physiol. 236:1481-1493.

Dumont NA, Wang YX, Rudnicki MA. 2015. Intrinsic and extrinsic mechanisms regulating satellite cell function. Development 142:1572-1581.

Fan Q, Li D, Cai L, Qiu X, Zhao Z, Wu J, Yang J, Lu Y. 2019. A novel mutation in the OAR domain of PITX3 associated with congenital posterior subcapsular cataract. BMC Med. Genet. 20:42.

García de la serrana D, Codina M, Capilla E, Jiménez-Amilburu V, Navarro I, Du SJ, Johnston IA, Gutiérrez J. 2014. Characterisation and expression of myogenesis regulatory factors during in vitro myoblast development and in vivo fasting in the gilthead sea bream (Sparus aurata). Comp. Biochem. Physiol. A Mol. Integr. Physiol. 167:90-99.

Halevy O, Piestun Y, Allouh MZ, Rosser BW, Rinkevich Y, Reshef R, Rozenboim I, Wleklinski-Lee M, Yablonka-Reuveni Z. 2004. Pattern of Pax7 expression during myogenesis in the posthatch chicken establishes a model for satellite cell differentiation and renewal. Dev. Dyn. 231:489-502.

Huang JD, Lee MF, Chang CF. 2002. The morphology of gonadal tissue and male germ cells in the protandrous black porgy, Acanthopagrus schlegeli. Zool. Stud. 41:216-227.

Jun S and Desplan C. 1996. Cooperative interactions between paired domain and homeodomain. Development 122:26392650.

Kwon HC, Zhang CI, Shin YJ, Kim KH, Kim JI, Seo YI. 2009. Maturation and spawning of black seabream Acanthopagrus schlegeli in the southern sea of Korea. Korean J. Ichthyol. 21:93-99.

Mayran A, Pelletier A, Drouin J. 2015. Pax factors in transcription and epigenetic remodelling. Semin. Cell Dev. Biol. 44:135-144.

Montarras D, L'honoré A, Buckingham M. 2013. Lying low but ready for action: the quiescent muscle satellite cell. FEBS J. 280:4036-4050.

Nicklas S, Otto A, Wu X, Miller P, Stelzer S, Wen Y, Kuang S, Wrogemann K, Patel K, Ding H, Schwamborn JC. 2012. TRIM32 regulates skeletal muscle stem cell differentiation and is necessary for normal adult muscle regeneration. PLoS One 7:e30445.

Pawlikowski B, Lee L, Zuo J, Kramer RH. 2009. Analysis of human muscle stem cells reveals a differentiation-resistant progenitor cell population expressing Pax7 capable of selfrenewal. Dev. Dyn. 238:138-149.

Pelletier A, Mayran A, Gouhier A, Omichinski JG, Balsalobre A, Drouin J. 2021. Pax7 pioneer factor action requires both paired and homeo DNA binding domains. Nucleic Acids Res. 49:7424-7436.

Ramírez-Espinosa JJ, González-Dávalos L, Shimada A, Piña E, Varela-Echavarria A, Mora O. 2016. Bovine (Bos taurus) bone marrow mesenchymal cell differentiation to adipogenic and myogenic lineages. Cells Tissues Organs 201:5164.

Rudnicki MA and Jaenisch R. 1995. The MyoD family of transcription factors and skeletal myogenesis. Bioessays 17:203209.

Seger C, Hargrave M, Wang X, Chai RJ, Elworthy S, Ingham PW. 2011. Analysis of Pax7 expressing myogenic cells in zebrafish muscle development, injury, and models of disease. Dev. Dyn. 240:2440-2451.

Shi X and Garry DJ. 2006. Muscle stem cells in development, regeneration, and disease. Genes Dev. 20:1692-1708.

Underhill DA and Gros P. 1997. The paired-domain regulates DNA binding by the homeodomain within the intact Pax-3 protein. J. Biol. Chem. 272:14175-14182.

von Maltzahn J, Jones AE, Parks RJ, Rudnicki MA. 2013. Pax7 is critical for the normal function of satellite cells in adult skeletal muscle. Proc. Natl. Acad. Sci. U. S. A. 110:16474-16479.

Wang L, Zhang W, Gladstone S, Ng WK, Zhang J, Shao Q. 2019. Effects of isoenergetic diets with varying protein and lipid levels on the growth, feed utilization, metabolic enzymes activities, antioxidative status and serum biochemical parameters of black sea bream (Acanthopagrus schlegelii). Aquaculture 513:734397.

Weber CM, Martindale MQ, Tapscott SJ, Unguez GA. 2012. Acti- 
vation of Pax7-positive cells in a non-contractile tissue contributes to regeneration of myogenic tissues in the electric fish S. macrurus. PLoS One 7:e36819.

Wu GC, Dufour S, Chang CF. 2021. Molecular and cellular regulation on sex change in hermaphroditic fish, with a special focus on protandrous black porgy, Acanthopagrus schlegelii. Mol. Cell. Endocrinol. 520:111069.

Zammit P and Beauchamp J. 2001. The skeletal muscle satellite cell: stem cell or son of stem cell? Differentiation 68:193-204.
Zaret KS and Carroll JS. 2011. Pioneer transcription factors: establishing competence for gene expression. Genes Dev. 25:2227-2241.

Zhou F, Shao Q, Xiao J, Peng X, Ngandzali BO, Sun Z, Ng WK. 2011. Effects of dietary arginine and lysine levels on growth performance, nutrient utilization and tissue biochemical profile of black sea bream, Acanthopagrus schlegelii, fingerlings. Aquaculture 319:72-80. 